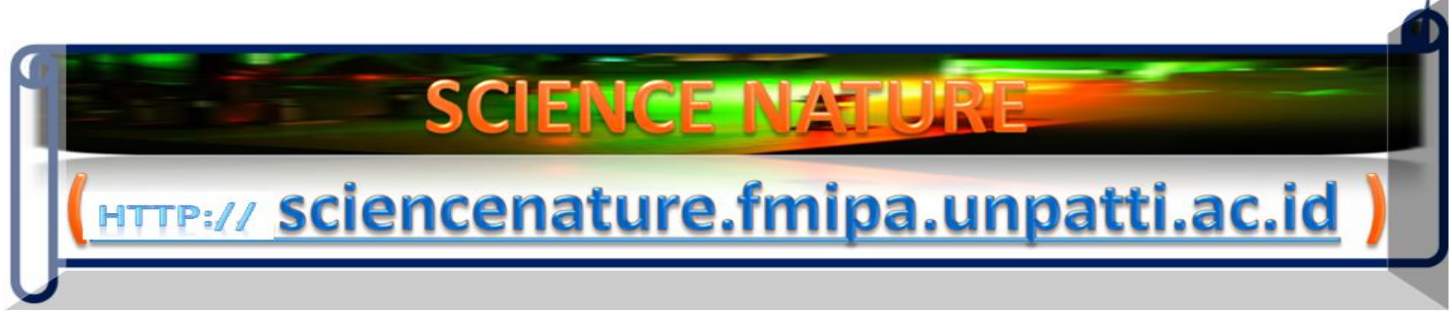

Science Nature 2(3), pp.177-191 (2019)

e-ISSN: 2654-6264

DOI: https://doi.org/10.30598/SNVol2Iss3pp177-191year2019

\title{
Grouping of Tectonic Earthquakes in the Province of Nusa Tenggara Barat Indonesia with K-Means Cluster Method Approach and Determination of Distribution Type
}

\author{
Henry Junus Wattimanela ${ }^{1,+}$ \\ ${ }^{1}$ Mathematics Department, Statistics Study Program, Faculty of Mathematics and Natural Sciences, \\ Pattimura University, Jl. Ir. M. Putuhena, Poka, Ambon city, Maluku province, Indonesia 97233
}

Received : September 1, 2019

Revised : September 12, 2019

Published : September 13, 2019

Copyright @ All rights are reserved by Henry J. Wattimanela

Corresponding author: Email: ${ }^{+}$hwattimanela@yahoo.com 


\section{Abstract}

The earthquake is one of the natural disasters that is destructive and claimed lives at a certain magnitude and depth. Indonesia is an earthquake-prone area because it is in the area of major tectonic plates. Province of Nusa Tenggara Barat is one of the 34 provinces in Indonesia which is earthquake prone. In this research, earthquake grouping will be carried out in the Province of Nusa Tenggara Barat using the K-Means cluster approach. Furthermore, using the Kolmogorov-Smirnov test the type of distribution is determined for each group variable resulting from the cluster process. The data used was the 2018 earthquake data in West Nusa Tenggara Province, sourced from the USGS earthquake catalog. The software used in this research process is SPSS, GMT, and Matlab, respectively. The results of this study are expected to be used as a reference for the Government of Nusa Tenggara Barat Province and surrounding areas related to earthquake disaster mitigation, especially evaluation of spatial and regional.

Keywords: Cluster, earthquake, Nusa Tenggara Barat (NTB), tectonic plate, Kolmogorov-Smirnov test, distribution

\section{ARTICLES}

\section{INTRODUCTION}

One of the natural phenomena that its occurrence is random and has a certain distribution is an earthquake event. Earthquake measurements are based on intensity and how strong an earthquake is felt. The impact of an earthquake with a magnitude (Richter Scale (SR)) of a certain
The invented contribution: Earthquake disaster mitigation evaluated using K-Means cluster approach with the type of distribution was extracted by the use of Kolmogorov-Smirnov test from the cluster process.

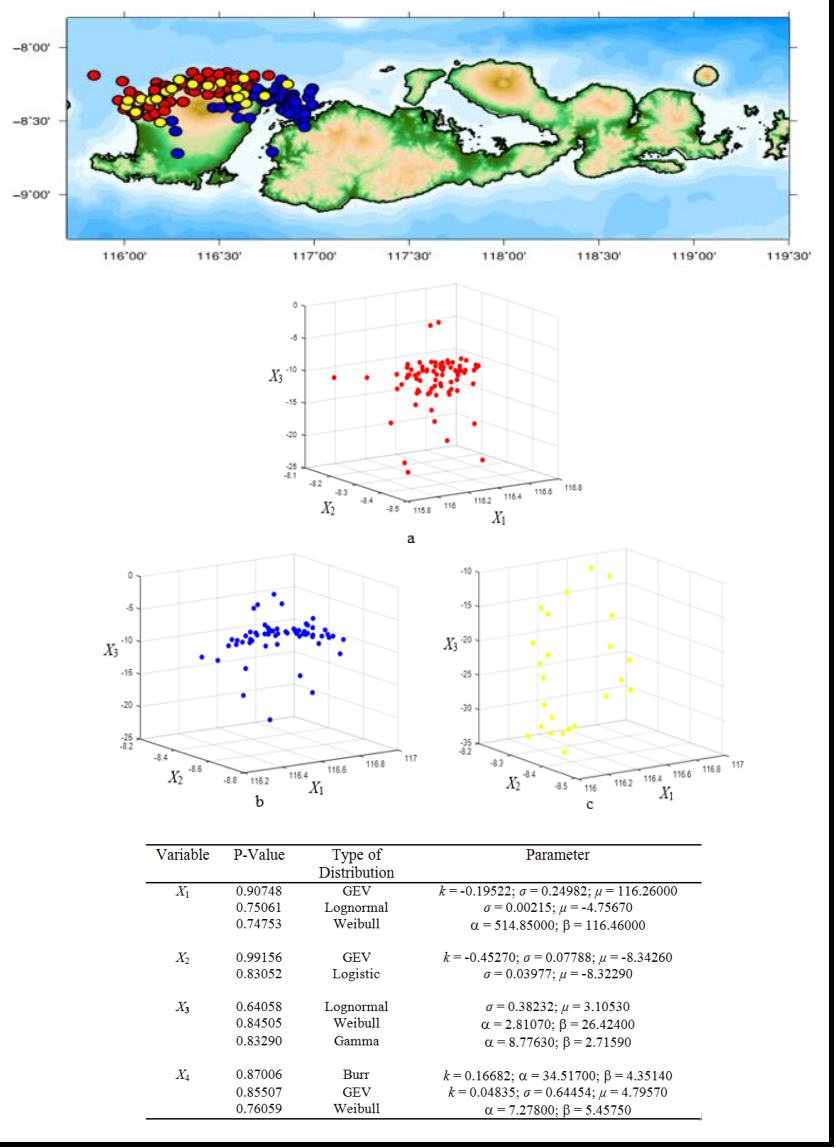

magnitude and a certain depth of the hypocenter below the earth's surface (in kilometers) can cause fatalities and large material losses.

Indonesia is one of the world's archipelago countries which is disposed to experiencing tectonic earthquakes. This is due to the fact that the Indonesian archipelago is at the confluence of major plates, namely the Eurasian, Indo-Australian and Pacific plates as depicted in Fig. 1. Many tectonic earthquake events have claimed many 
lives, destroyed homes and office buildings in several locations in the Indonesian archipelago.

According to the Directorate of Volcanology and Geological Disaster Mitigation (DVGDM) of the Department of Energy and Mineral Resources in Indonesia, the Province of Nusa Tenggara Barat (NTB) is one of 28 regions in Indonesia declared earthquake and tsunami prone. This is because the Province of NTB is above 3 major plates, resulting in the formation of a complex geological order. This part of the region is part of the Eurasian plate, which moves relative to the southeast interacting with the Indian-Australian plate which moves relative to the north and the Pacific plate that moves relative to the west. The meeting zone between the 3 plates forms a trough known as a subduction zone. In addition, as a result of the collisions formed faults in the NTB Region [1,2].

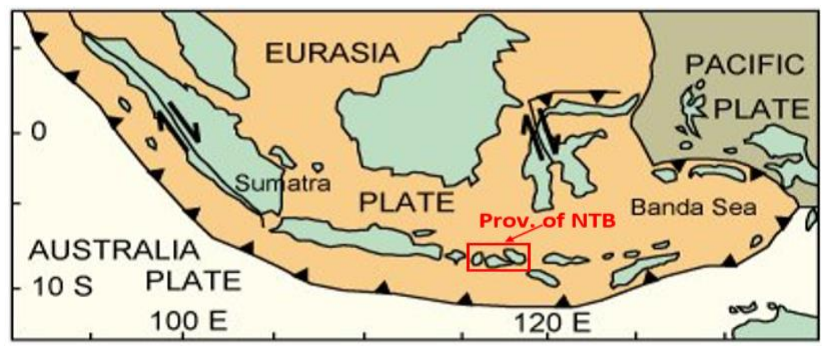

Figure 1. Indonesian Tectonic Plates [3].

(Source:http://www.drgeorgepc.com/Tsunami1833 Indonesia. html).

NTB Province has an area of 20,153.20 km2 which is an island province because it consists of hundreds of islands as shown in Fig. 2. Sumbawa Island and Lombok Island are the 2 major islands in Province of NTB out of 32 inhabited islands (Statistics of West Nusa Tenggara Province, 2018).

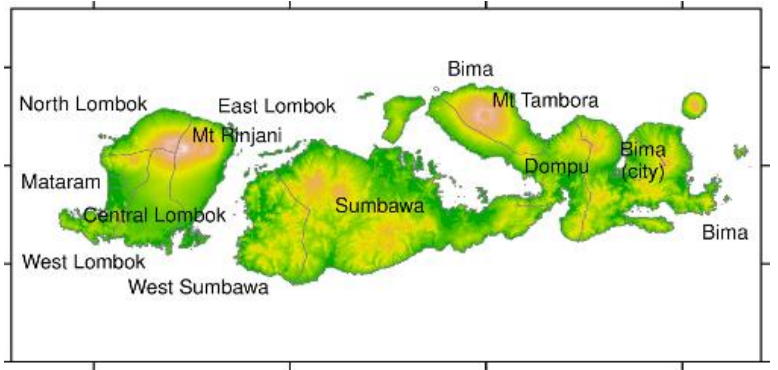

Figure 2. Province of NTB [4].

It is still fresh in our memories when there were several earthquakes in Province of NTB, Indonesia in 2018, which caused heavy casualties and material losses. Province of NTB experienced an earthquake with a magnitude $>6$ and a depth of $<25 \mathrm{~km}$ that occurred consecutively on 29 July 2018, 5 August 2018, 9 August 2018, and 19 August 2108, respectively. One of the causes of the earthquake in Province of NTB, specifically the northern part of Lombok Island there is the Arch Thrust Zone, South there is a mega thrust, West and East there is a sliding fault system. In addition, due to a shift of the upward fault on the Lombok Island Arc (the rear arc fault zone of Nusa Tenggara). These faults start from Alor-Wetar Island, Flores, Sumbawa and Lombok to Bali [5]. The impact of the earthquake from July 29, 2018 to August 26, 2018 included 565 victims, 1,116 seriously injured/hospitalized, 3981 damaged houses 71,937, and 417,525 refugees. The regency with the most fatalities and injuries was East Lombok Regency while the largest heavily damaged house was in North Lombok Regency [6].

At present several statistical techniques have been developed and applied to several earthquake cases such as those examined by Parwanto and Oyama in 2014 [7] utilizing the exponential distribution and Poisson distribution to investigate quantitatively the tendency of earthquake and tsunami natural disasters. On the other hand, in Ref. [8] see a correlation between the amount of elastic energy stored in the slab core and the distribution of 
earthquake frequency depths for various viscosities, lithosphere and lithosphere nuclei. Then according to Zuo, et al. in 2009 [9] applied the point process to model the point patterns that often occur in various fields of science including earthquakes. The point process approach is also applied Wattimanela et al. [10] in classifying earthquakes. Application of statistical and spectral analysis to detect possible ionospheric precursors from earthquakes by Oikonomou, et al. in 2017 [11] and Becar-Varela, et al. in 2016 [12] distinguish between explosions and earthquakes by using wavelet analysis. Then Brown, et al. in 2008 [13] used approach correlation and autocorrelation to identify low frequency earthquakes.

In this study, earthquake will be grouped in the region of Province of NTB with the K-Means cluster approach [14-16]. Furthermore, the results of grouping are plotted on a map of the NTB Province. Then the type of distribution of each variable of the grouping results will be determined using the Kolmogorov-Smirnov test [17-19]. Before determining the type of distribution, descriptive statistics, boxplots and scatterplots were analyzed $[17,19]$ The results of the analysis of research on the classification and mapping of earthquakes carried out is expected to be used as a reference for government of the NTB Province and surrounding in managing of earthquake mitigation programs and evaluation of spatial planning and territories.

\section{RESEARCH METHODS and DATA}

Earthquake data used in this study were sourced from the United States Geological Survey (USGS) catalog. The occurrence of the earthquake of 2018 in NTB Province was the focus of this study. Then the earthquake data is limited only to earthquake events with magnitude $>3$ SR and depth $\leq 50 \mathrm{~km}$. By choosing such criterion with the consideration that an earthquake with the aforementioned criteria has a significant impact on the damage and casualties that occur. This study only uses 6 variables namely longitude $\left(X_{1}\right)$, latitude $\left(X_{2}\right)$, depth $\left(X_{3}\right)$, magnitude $\left(X_{4}\right)$, date $\left(X_{5}\right)$, and location source $\left(X_{6}\right)$ of a total of 18 available variables. Many 2018 earthquake events with magnitude $>3 \mathrm{SR}$ dan depth $\leq 50 \mathrm{~km}$ are 165 events and the distribution of earthquakes is dominant on the island of Lombok and its surroundings. The distribution of earthquake can be shown in Fig. 3.

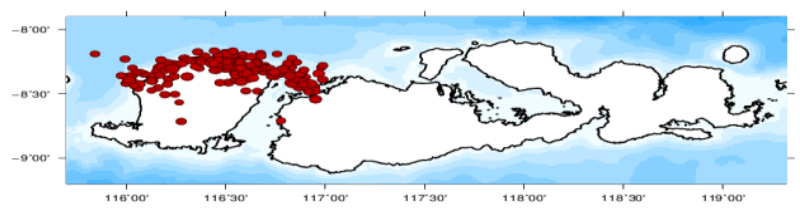

Figure 3. Earthquakes distribution 2018 in Province of NTB.

This research was preceded by a literature review from various data sources and documents $[3,6,20-22]$ obtained by the determination of data sources and criteria. Then a study based on descriptive statistics is the data of exposure with figures or pictures that are informative so that it can be obtained from temporary conclusions. It is related to boxplots and scatterplots (2 and 3 dimensions (2D and 3D)). The next stage is the earthquake grouping using K-means non-hierarchical cluster method. The number of clusters is determined based on the distribution of earthquake data on 2-dimensional scatterplots. Furthermore, the results of earthquake grouping will be analyzed for each cluster as a result of the cluster that has been done before with a consolidation analysis related to the location of the earthquake. In the next step, do the mapping and analysis of earthquake event data in Province of NTB based on each cluster produced in the clustering process. The next step is to carry out the 
Kolmogorov-Smirnov test to determine the type of data distribution of variable longitude $\left(X_{1}\right)$, latitude $\left(X_{2}\right)$, depth $\left(X_{3}\right)$, and magnitude $\left(X_{4}\right)$ for each cluster produced using the K-Means cluster method. Then also a chart of histograms and density functions of each distribution which has been determined by all variables for each cluster.

\section{RESULTS AND DISCUSSION}

\subsection{Earthquake Grouping with K-Mean Cluster Approach}

The 2018 Earthquakes were grouped using the K-Means (non-hierarchical) cluster approach. This approach is used when taking into consideration the large size of the data. Determination of the number of clusters (groups) based on the subjectivity of researchers by considering the earthquakes distribution of scatterplot variables $X_{1}$ and $X_{2}$ as shown in Fig. 4.

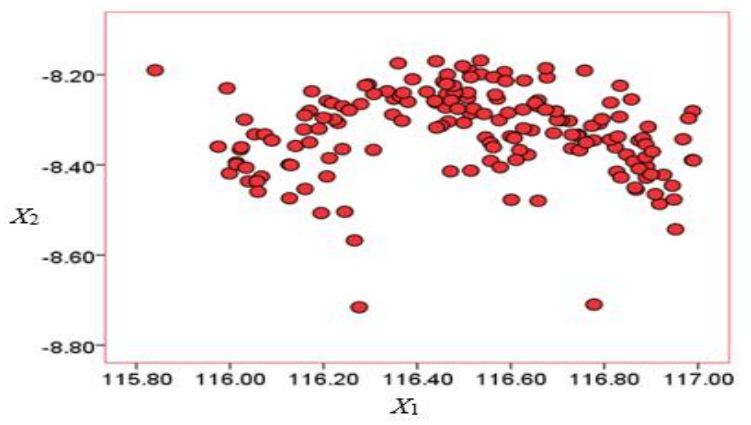

Figure 4. Scatterplot of earthquakes 2018 based on $X_{1}$ and $X_{2}$ in Province of NTB.

According to the scatterplot results in Fig. 4, one obtains that in general there is data clustered into 3 clusters and some data are spread. Then the cluster process is performed on the variables that have been determined namely the location of the earthquake, latitude, longitude, depth and magnitude. The following Table $\mathbf{1}$ is the first display of the data clustering process before iterating the previous standardization because the data used varies in units. Next iterations are performed in the clustering process and it turns out that the iteration is carried out through 10 stages to get the right cluster and the minimum distance between cluster centers that occur from the iteration results is 6.302. The final results of the clustering process are shown in Table 2.

Table 1. Clustering process of 2018 earthquake data in Province of NTB (before iteration).

\begin{tabular}{|l|c|c|c|}
\hline \multirow{2}{*}{\multicolumn{1}{|c|}{ Variable }} & $\mathbf{3}$ & \multicolumn{3}{|c|}{ Cluster } \\
\cline { 2 - 4 } & 1.45480 & $\mathbf{2}$ & $\mathbf{3}$ \\
\hline Zscore: $X_{1}$ & -2.35541 & 0.93162 & 0.40246 \\
\hline Zscore: $X_{2}$ & -0.41887 & -0.41887 & 1.33387 \\
\hline Zscore: $X_{3}$ & -0.76757 & -0.96064 & 4.44514 \\
\hline Zscore: $X_{4}$ & & & 0.09071 \\
\hline
\end{tabular}

Table 2. The Final Results of the 2018 Earthquake Data Clustering Process in Province of NTB.

\begin{tabular}{|l|c|c|c|}
\hline \multirow{2}{*}{\multicolumn{1}{|c|}{ Variable }} & $\mathbf{3}$ Cluster \\
\cline { 2 - 4 } & $\mathbf{1}$ & $\mathbf{2}$ & $\mathbf{3}$ \\
\hline Zscore: $X_{1}$ & 0.49342 & -0.62958 & 0.04905 \\
\hline Zscore: $X_{2}$ & -0.55606 & 0.88867 & -0.52558 \\
\hline Zscore: $X_{3}$ & -0.24588 & -0.37585 & 1.78573 \\
\hline Zscore: $X_{4}$ & -0.23541 & -0.15161 & 1.16306 \\
\hline
\end{tabular}

Based on the Anova table, the probability value ( $\mathrm{sig}$ ) is less than 0.05 , so it can be concluded that there are differences in the variables in cluster 1 , cluster 2, and cluster 3 . The number of earthquake events in cluster 1 is 78 events, cluster 2 is 63 events, and cluster 3 is 24 events. The number of earthquake events in cluster 1 , cluster 2 and cluster 3 based on regency areas in NTB Province can be shown by Table 3 . 
Table 3. Number of 2018 Earthquake Events for Cluster 1, Cluster 2, and Cluster 3 by Regencies in Province of NTB.

\begin{tabular}{|l|l|l|l|l|}
\hline \multirow{2}{*}{ Regency } & \multicolumn{3}{c|}{ Cluster } & \multirow{2}{*}{ Total } \\
\cline { 2 - 5 } & \multicolumn{1}{|c|}{$\mathbf{2}$} & \multicolumn{1}{c|}{$\mathbf{2}$} & \multicolumn{1}{|c|}{3} & \\
\hline East Lombok & 30 & 33 & 10 & 73 \\
\hline North Lombok & 48 & 0 & 13 & 61 \\
\hline West Lombok & 0 & 2 & 1 & 3 \\
\hline Central Lombok & 0 & 2 & 0 & 2 \\
\hline Sumbawa & 0 & 25 & 0 & 25 \\
\hline West Sumbawa & 0 & 1 & 0 & 1 \\
\hline Total & 78 & 63 & 24 & 165 \\
\hline
\end{tabular}

The distribution of earthquake results from clustering can be shown with Fig. 5. Based on Fig. $\mathbf{5}$, earthquakes location in cluster 1 is indicated by red colour, cluster 2 is shown in blue, and yellow colour indicates earthquakes location of cluster 3 .

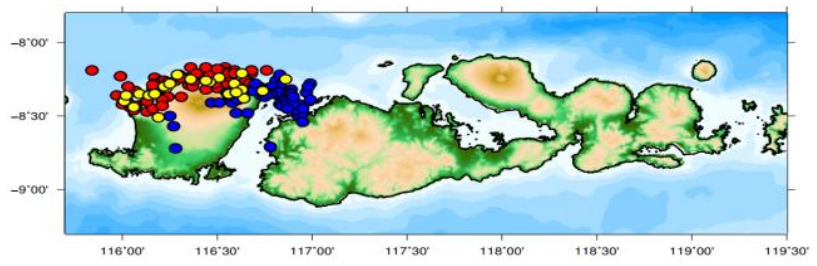

Figure 5. Distribution of earthquakes for Cluster 1, cluster 2, and cluster 3 in Province of NTB.

The scatterplot can be shown for the distribution of earthquake clusters 1 , cluster 2 , and cluster 3 based on data of $X_{1}, X_{2}$, dan $X_{3}$ variables as shown in Fig. 6.

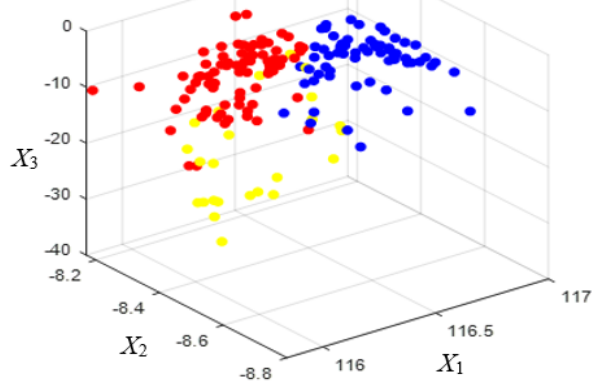

Figure 6. Scatterplot based on $X_{1}, X_{2}$, and $X_{3}$ of 2018 earthquake data in Province of NTB for cluster 1, cluster 2, and cluster 3.

Based on Fig. 6, it seems that deeper earthquakes are less frequent compared to earthquakes that spread closer to the surface. Clusters 1 and clusters 2 occur frequently in $X_{3}$ at intervals of $10 \leq X_{3} \leq 20 \mathrm{~km}$ while earthquake events for cluster 3 spread at $X_{3}$ intervals of around $15 \leq X_{3} \leq 40 \mathrm{~km}$. The tectonic earthquake for cluster 1 can be shown with Fig. 7. Based on Fig. 7 it appears that the distribution of earthquakes occurs dominant in the Regency of East Lombok and North Lombok.

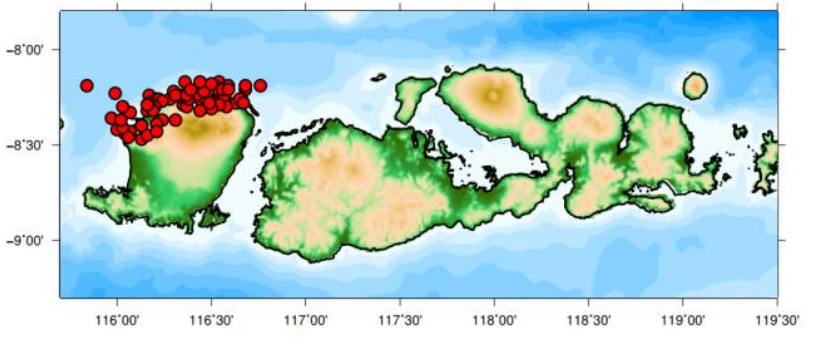

Figure 7. Distribution of earthquake for Cluster 1 in Province of NTB.

The tectonic earthquake distribution in Province of NTB for Cluster 2 can be shown with Fig. 8. Based on Fig. 8, the distribution of earthquake occurred dominant in East Lombok Regency and surrounding areas. 


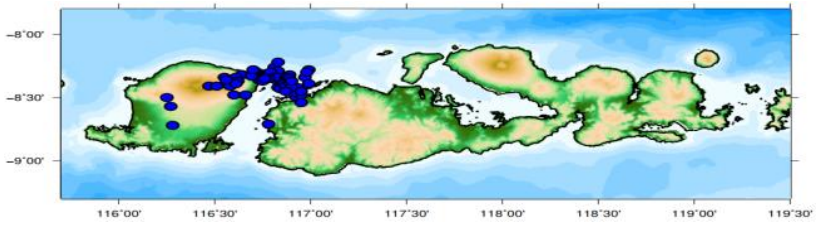

Figure 8. Distribution of earthquake for Cluster 2 in Province of NTB.

On the other side, the dominant earthquake distribution for Cluster 3 occurred in North Lombok and East Lombok Regencies as shown in Fig. 9.

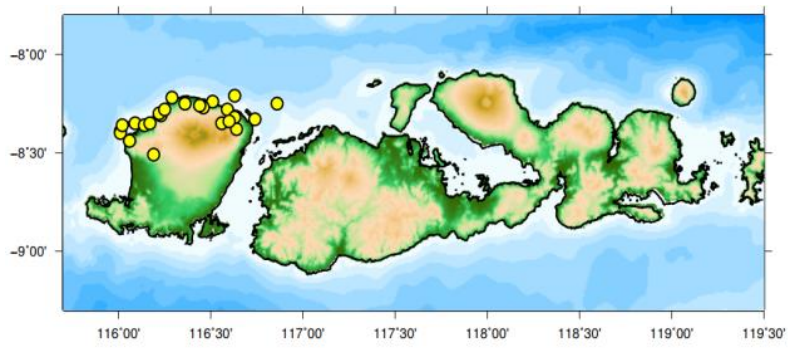

Figure 9. Distribution of earthquake for Cluster 3 in Province of NTB.

Scatterplot of earthquake for cluster 1 based on data of $X_{1}, X_{2}$, and $X_{3}$ can be shown with Fig. 10.a. Based on Fig. 10.a can be seen that the distribution of earthquake occurs at depth intervals of $10 \leq X_{3} \leq 17 \mathrm{~km}$ and rarely occurs at depth intervals of $0 \leq X_{3} \leq 9 \mathrm{~km}$ and $18 \leq X_{3} \leq 25$ $\mathrm{km}$. Furthermore, it can be shown the distribution of cluster 2 earthquake activity using scatterplots based on earthquake data of $X_{1}, X_{2}$, and $X_{3}$ as shown in Fig. 10.b. Moreover, Fig. 10.b shows that earthquakes often occur at depth intervals of $10 \leq X_{3} \leq 14 \mathrm{~km}$ while the opposite is rare in intervals $X_{3}<10 \mathrm{~km}$ and $X_{3}>14 \mathrm{~km}$. Then, it can be shown the scatterplot of cluster 3 earthquake events based on $X_{1}, X_{2}$, and $X_{3}$ data as shown in Fig. 10.c. It is seen that earthquake events do not accumulate at certain depth intervals but spread along depth intervals of $11 \leq X_{3} \leq 33 \mathrm{~km}$.
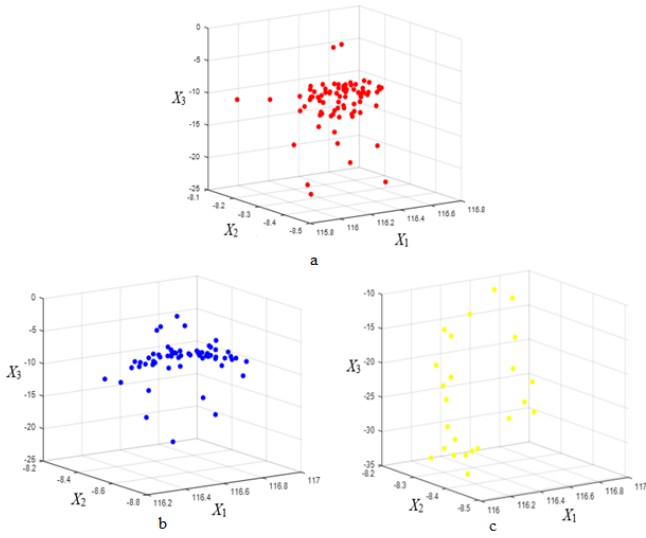

Figure 10. Scatterplot of $X_{1}, X_{2}$, and $X_{3}$ earthquake data in Province of NTB a. Cluster 1, b. Cluster 2, and c. Cluster 3.

Descriptive statistics based on earthquake variable data of $X_{1}, X_{2}, X_{3}$, and $X_{4}$ per cluster can be shown in Table 4, Table 5, and Table 6, respectively.

Table 4. Descriptive statistics based on earthquake variable data of $X_{1}$, $X_{2}, X_{3}$, dan $X_{4}$ in Province of NTB for cluster 1 .

\begin{tabular}{cccccccc}
\hline Variable & N & Min & Max & Mean & $\begin{array}{c}\text { Standart } \\
\text { Deviation }\end{array}$ & Skewness & Kurtosis \\
\hline$X_{1}$ & 78 & 115.84 & 116.76 & 116.3546 & 0.21285 & -0.299 & -0.854 \\
$X_{2}$ & 78 & -8.47 & -8.17 & -8.2815 & 0.07643 & -0.786 & -0.105 \\
$X_{3}$ & 78 & 3.30 & 24.47 & 11.0856 & 3.53830 & 2.187 & 6.144 \\
$X_{4}$ & 78 & 3.80 & 5.40 & 4.4756 & 0.31050 & 0.720 & 0.859 \\
\hline
\end{tabular}

Table 5. Descriptive statistics based on earthquake variable data of $X_{1}$, $X_{2}, X_{3}$, dan $X_{4}$ in Province of NTB for cluster 2.

\begin{tabular}{ccrrrcrr}
\hline Variable & N & Min & \multicolumn{1}{c}{ Max } & Mean & $\begin{array}{c}\text { Standart } \\
\text { Deviation }\end{array}$ & Skewness & Kurtosis \\
\hline$X_{1}$ & 63 & 116.25 & 116.99 & 116.7659 & 0.17060 & -1.257 & 1.584 \\
$X_{2}$ & 63 & -8.72 & -8.22 & -8.3870 & 0.09103 & -1.557 & 3.912 \\
$X_{3}$ & 63 & 3.85 & 22.95 & 10.2700 & 2.71166 & 2.457 & 10.161 \\
$X_{4}$ & 63 & 3.70 & 5.50 & 4.5190 & 0.41615 & 0.699 & -0.182 \\
\hline
\end{tabular}


Table 6. Descriptive statistics based on earthquake variable data of $X_{1}$, $X_{2}, X_{3}$, dan $X_{4}$ in Province of NTB for cluster 3.

\begin{tabular}{ccrrrcrr}
\hline Variable & N & Min & \multicolumn{1}{c}{ Max } & Mean & $\begin{array}{c}\text { Standart } \\
\text { Deviation }\end{array}$ & Skewness & Kurtosis \\
\hline$X_{1}$ & 24 & 116.01 & 116.86 & 116.3625 & 0.25523 & 0.194 & -1.175 \\
$X_{2}$ & 24 & -8.51 & -8.21 & -8.3229 & 0.07214 & -0.609 & 0.513 \\
$X_{3}$ & 24 & 10.00 & 34.56 & 23.8358 & 8.04588 & -0.288 & -1.108 \\
$X_{4}$ & 24 & 4.10 & 6.90 & 5.2000 & 0.82304 & 0.741 & -0.374 \\
\hline
\end{tabular}

Based on Table 4, Table 5, and Table 6; it can be seen that the earthquake longitude data for cluster 3 has a high Standard Deviation (SD) value of 0.25523 if compared to the SD value of earthquake longitude data in cluster 1 and cluster 2 so that it can be said that the earthquake longitude data in cluster 3 has a wider variation range when compared to the earthquake longitude data for cluster 1 and cluster 2 . The negative skewness value $(<0)$ of earthquake longitude data for cluster 1 and cluster 2 shows that the distribution shape of earthquake longitude data in cluster 1 is negatively skewed because the tail is from the distribution point data referred to left. On the other hand, a positive skewness value (>0) of earthquake longitude data for cluster 3 indicates that the distribution shape of earthquake longitude data is positively skewed because the tail of the data distribution point is intended to the right. Furthermore, the kurtosis value of earthquake longitude data for cluster 1 , cluster 2 and cluster 3 has a value $<3$ so that the center of the data distribution has a flatter peak (platykurtic).

The earthquake latitude data in cluster 2 has a high SD which is 0.09103 when compared to SD of Cluster 1 and Cluster 3. This shows that earthquake latitude data in Cluster 2 is wider in the range of variation when compared to Cluster 1 and Cluster 3. The negative skewness value $(<0)$ for earthquake latitude data in cluster 1 indicates that the distribution shape of earthquake latitude data in cluster 1 is negative because the tail of the data distribution point is referred to the left. On the other hand, the positive skewers value $(>0)$ for the earthquake latitude data in cluster 2 and cluster 3 shows that the shape of the data distribution is positively skewed because the tail of the data distribution point is intended to the right. The kurtosis value of earthquake latitude data for cluster 1 and cluster 3 is smaller than $3(<3)$ so it shows that the center of the distribution of earthquake latitude data in cluster 1 and cluster 3 has a more horizontal peak (paltykurtic). On the other hand, the kurtosis value of earthquake latitude data in cluster 2 is greater than $3(>3)$. This shows that the center of the earthquake latitude data distribution in cluster 2 has a sharper peak.

Furthermore, based on Table 4, Table 5, and Table 6, earthquake depth data of cluster 3 has a high SD value that is 8.04588 when compared to cluster 1 and cluster 2 . This indicates that depth data in cluster 3 has a wide variation in range when compared with the earthquake depth data in cluster 1 and cluster 2 . The positive skewers value $(>0)$ for the earthquake depth data in cluster 1 and cluster 2 shows that the distribution shape of the earthquake depth data distribution in cluster 1 is negatively skewed because the tail from the data distribution point is intended to the left. On the other hand the negative skewness value $(<0)$ for the earthquake 2 and cluster 3 indicates that the shape of the data distribution is positive skewed because the tail of the data distribution point is intended to the right. The value of kurtosis of earthquake depth data in cluster 1 and clusters 2 is $>3$ so that the middle part of the data distribution has a rather sharp peak (leptokurtic). While the earthquake depth data of cluster 3 is $<3$, this means that the middle portion of earthquake depth data distribution in cluster 3 has a flatter peak (platykurtic).

The earthquake magnitude data of cluster 3 also has a high SD that is 0.82304 when compared to the earthquake magnitude data of cluster 1 and cluster 2 based on Table 4, Table 5, and Table 6. This 
means that the earthquake magnitude data of cluster 3 is wider in the range of variation when compared with cluster 1 and cluster 2 . The skewness value (> 0 ) for earthquake magnitude data of cluster 1 , cluster 2 and cluster 3 shows that distribution shape of earthquake magnitude distribution data is negative because the tail of the data distribution point is referred to the left. On the other hand, earthquake magnitude data in cluster 1 , cluster 2 , and cluster 3 have kurtosis values $<3$ so that the middle portion of the magnitude distribution of cluster 1 , cluster 2 and cluster 3 has a flat peak (platykurtic).

\subsection{Types of Clustering Results Data Distribution}

In this section, the determination of the type of distribution of earthquake data variables $X_{1}, X_{2}, X_{3}$, and $X_{4}$ in Province of NTB for cluster 1, cluster 2, and cluster 3. Before determining the type of distribution will be shown a boxplot based on variable earthquake data $X_{1}, X_{2}, X_{3}$, and $X_{4}$ in Province of NTB for cluster 1, cluster 2, and cluster 3. The following boxplot of earthquake data plot $X_{1}$ shows for cluster 1 , cluster 2 , and cluster 3 as embedded in Fig. 11.
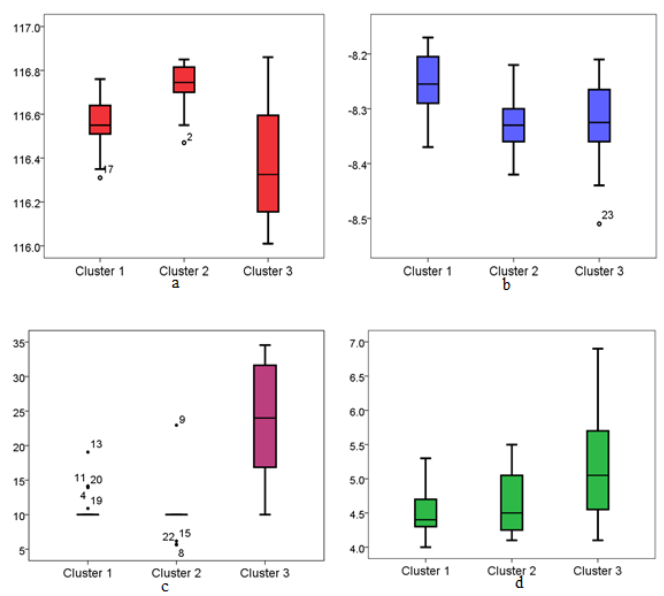

Figure 11. Boxplot for cluster 1, cluster 2, and cluster 3 based on earthquake data of a. $X_{1}$, b. $X_{2}$, c. $X_{3}$, and d. $X_{4}$.
Based on Fig. 11.a can be seen that there are outliers in earthquake data $X_{1}$ for cluster $1\left(17^{\text {th }}\right.$ data) and cluster $2\left(2^{\text {nd }}\right.$ data) while in cluster 3 there is no outliers. Then the data median value of Cluster 1 , Cluster 2, and Cluster 3 is not the same as the highest median value of $X_{1}$ data for Cluster 2 while the lowest is in Cluster 3. On the other hand it can be concluded that the $X_{1}$ data for Cluster 1, Cluster 2 , and Cluster 3 asymmetrical and different of data distribution. The highest variance in $X_{1}$ data for cluster 3 is due to the wide boxplot shape (Fig. 11.a). The minimum data is 116 and the maximum is below 117. Then a boxplot will be shown from the $X_{2}$ data for cluster 1 , cluster 2 , and cluster 3 with Fig. 11.b. Based on Fig. 11.b shows that there is outliers data in $X_{2}$ data for cluster 3, that is $23 \mathrm{r}^{\mathrm{d}}$ data while in cluster 1 and cluster 2 there is none. Based on Fig. 11.b, $X_{2}$ data for cluster 1 and cluster 3 look asymmetrical while cluster 2 looks almost symmetrical and the location of the median value is different. The highest median value is in Cluster 1 of data $X_{2}$ with the maximum number below -8.2 while the minimum number is above -8.4 . Very low variance is in the $X_{2}$ data for cluster 2 with a minimum number above -8.5 while the maximum is under -8.2. The boxplots of $X_{3}$ data for cluster 1 , cluster 2, and cluster 3 can be shown with Fig. 11.c. Based on the boxplot of $X_{3}$ data as shown in Fig. 11.c shows that cluster 1 has many outliers $\left(4^{\text {th }}\right.$, $11^{\text {th }}, 13^{\text {th }}, 19^{\text {th }}$ and $20^{\text {th }}$ data) because it has a very high value above the normal diversity while cluster 2 also has some outliers $\left(8^{\text {th }}, 9^{\text {th }}, 15^{\text {th }}\right.$, and $22^{\text {nd }}$ data ) because it has a very high value above normal diversity and has the lowest value below normal diversity.

Cluster 3 has no outlier value and has a high variance. On the other hand, $X_{3}$ data for cluster 1 and cluster 2 has a low variance. Based on Fig. 11.c, it also appears that the highest median value is in cluster 1 while the lowest median value is in cluster 2. Boxplots of $X_{4}$ data for cluster 1 , cluster 2 
and cluster 3 can be shown with Fig. 11.d. In Fig.

11.d, it appears that the data $X_{4}$ for cluster 1 , cluster 2 , and cluster 3 is not symmetrical with the location of the median value is not the same. The highest median value is in cluster 3 while the lowest is in cluster 1 . On the other hand, the data $X_{4}$ variance for cluster 3 is very high. This can be seen that the boxplot shape is wide as depicted in Fig. 11.d. The minimum number is at 4.1 while the maximum number is close to 7.0 .

Based on the boxplots of $X_{1}, X_{2}, X_{3}$, and $X_{4}$ data for cluster 1 , cluster 2 , and cluster 3 it can be assumed that the data distribution is not normal but tends to be other types of distribution. For this reason, the type of data distribution $X_{1}, X_{2}, X_{3}$, and $X_{4}$ for the three clusters will be determined by testing the distribution type. The distribution test used in this study is the Kolmogorov-Smirnov Test (K-S) with $\alpha=0.05$.

The process of testing the distribution type on the $X_{1}$ earthquake data in Province of NTB for cluster 1 using the K-S test shows that the $X_{1}$ earthquake data follows several distributions namely the Burr, GEV, and Lognormal distribution. However, $X_{1}$ earthquake data of cluster 1 tends to follow the Burr distribution because the P-value is greater so it can be concluded that $X_{1}$ earthquake data of cluster 1 is closer to the Burr distribution. In detail the results of the test can be shown in Table 7. Furthermore, histogram and density function graph of the Burr, GEV, and Lognormal distribution are made as shown in Fig. 12.a. Based on Fig. 12.a, it appears that $X_{1}$ earthquake data is more likely to follow the Burr distribution. Then the histogram graph shows that the $X_{1}$ earthquake data is not symmetrical (the histogram and density function graph are negative skewed) so that it can be concluded that $X_{1}$ earthquake data of cluster 1 is not normally distributed. On the other hand, testing of the type of distribution was also carried out using the K-S test for cluster 2.

The test of data distribution results can be shown by Table 8. Based on Table 8, it can be seen that the Weibull distribution has a large P-value when compared to the other two distributions so it can be concluded that $X_{1}$ earthquake data of cluster 2 follows the Weibull distribution. This can be shown by the Weibull density function graph and histogram shown by Fig. 13.a. Based on Fig. 13.a shows that the histogram and graph of the Weibull density function are negatively skewed so that it can be concluded that the $X_{1}$ earthquake data is not normally distributed. Furthermore, testing the distribution type for $X_{1}$ earthquake data of cluster 3 also using the K-S test and the results can be shown in detail with Table 9.

Table 7. K-S test results of earthquakes data $X_{1}, X_{2}, X_{3}$, dan $X_{4} 2018$ cluster 1 in Province of NTB.

\begin{tabular}{cccc}
\hline Variable & P-Value & $\begin{array}{c}\text { Type of } \\
\text { Distribution }\end{array}$ & Parameter \\
\hline$X_{1}$ & 0.45920 & Burr & $k=14.12900 ; \alpha=657.81000 ; \beta=116.92000$ \\
& 0.45628 & GEV & $k=-0.43563 ; \sigma=0.23048 ; \mu=116.29000$ \\
& 0.12353 & Lognormal & $\alpha=0.00182 ; \beta=4.75660$ \\
$X_{2}$ & & & \\
& 0.64308 & GEV & $k=-0.64318 ; \sigma=0.08457 ; \mu=-8.24480$ \\
& 0.09352 & Logistic & $\sigma=0.04214 ; \mu=-8.28150$ \\
$X_{3}$ & -- & -- & -- \\
& & & \\
$X_{4}$ & 0.13864 & Burr & $k=0.43450 ; \alpha=40.44300 ; \beta=4.27690$ \\
& 0.13553 & GEV & $\mathrm{k}=-0.02007 ; \sigma=0.24895 ; \mu=4.33680$ \\
& 0.01274 & Gamma & $\alpha=207.77000 ; \beta=0.02154$ \\
\hline
\end{tabular}

Table 8. K-S test results of earthquakes data $X_{1}, X_{2}, X_{3}$, dan $X_{4} 2018$ cluster 2 in Province of NTB.

\begin{tabular}{cccc}
\hline Variable & P-Value & $\begin{array}{c}\text { Type of } \\
\text { Distribution }\end{array}$ & Parameter \\
\hline$X_{1}$ & 0.80701 & GEV & $k=-0.78438 ; \sigma=0.18495 ; \mu=116.75000$ \\
& 0.24166 & $\begin{array}{c}\text { Lognormal } \\
\text { Weibull }\end{array}$ & $\sigma=0.00145 ; \mu=4.76820$ \\
& 0.81873 & & $\alpha=805.56000 ; \beta=116.84000$ \\
$X_{2}$ & 0.47978 & GEV & $k=-0.71304 ; \sigma=0.09507 ; \mu=-8.39880$ \\
& 0.42897 & Logistic & $\sigma=0.05019 ; \mu=-8.38700$ \\
$X_{3}$ & -- & -- & -- \\
& & & \\
$X_{4}$ & 0.74318 & Burr & $k=0.33211 ; \alpha=35.34500 ; \beta=4.18480$ \\
& 0.58451 & GEV & $\mathrm{k}=0.01394 ; \sigma=0.33030 ; \mu=4.32380$ \\
& 0.08070 & Gamma & $\alpha=117.92000 ; \beta=0.03832$ \\
\hline
\end{tabular}


Table 9. K-S test results of earthquakes data $X_{1}, X_{2}, X_{3}$, dan $X_{4}$ 2018 cluster 3 in Province of NTB.

\begin{tabular}{cccc}
\hline Variable & P-Value & $\begin{array}{c}\text { Type of } \\
\text { Distribution }\end{array}$ & Parameter \\
\hline$X_{1}$ & 0.90748 & GEV & $k=-0.19522 ; \sigma=0.24982 ; \mu=116.26000$ \\
& 0.75061 & Lognormal & $\sigma=0.00215 ; \mu=-4.75670$ \\
& 0.74753 & Weibull & $\alpha=514.85000 ; \beta=116.46000$ \\
$X_{2}$ & 0.99156 & GEV & $k=-0.45270 ; \sigma=0.07788 ; \mu=-8.34260$ \\
& 0.83052 & Logistic & $\sigma=0.03977 ; \mu=-8.32290$ \\
$X_{3}$ & 0.64058 & Lognormal & $\sigma=0.38232 ; \mu=3.10530$ \\
& 0.84505 & Weibull & $\alpha=2.81070 ; \beta=26.42400$ \\
& 0.83290 & Gamma & $\alpha=8.77630 ; \beta=2.71590$ \\
$X_{4}$ & 0.87006 & Burr & $k=0.16682 ; \alpha=34.51700 ; \beta=4.35140$ \\
& 0.85507 & GEV & $k=0.04835 ; \sigma=0.64454 ; \mu=4.79570$ \\
& 0.76059 & Weibull & $\alpha=7.27800 ; \beta=5.45750$ \\
\hline
\end{tabular}

Based on Table 9, it can be seen that the $X_{1}$ earthquake data in cluster 3 follows three types of distribution, namely GEV, Lognormal, and Weibull distribution. Furthermore, it can be concluded that $X_{1}$ earthquake data of cluster 3 tends to follow the GEV distribution. This is further confirmed by the P-value of the GEV distribution which is greater when compared to the other two distributions. Next the histogram and graph of the three distribution density functions referred to as Fig. 14.a. Based on Fig. 14.a shows that histogram graph of GEV distribution density function is positively skewed so it can also be concluded that the earthquake data in cluster $X_{1}$ is not normally distributed.

The $X_{2}$ earthquake data of cluster 1 was tested using the K-S test and the results can be shown in Table 7. Based on such data in Table 7, one finds $X_{2}$ earthquake data follows GEV and Logistics distribution. However, P-value of the GEV distribution is greater than the logistic distribution so that it can be concluded that $X_{2}$ earthquake data of cluster 1 is distributed by GEV. The histogram and graph density function of the GEV and logistics distribution can be shown with Fig. 12.b. Based on Fig. 12.b shows that the histogram and graph of the density function of two distributions are negatively skewed so that it can also be concluded that the $X_{2}$ earthquake data of cluster 1 is not normally distributed. Furthermore, $X_{2}$ earthquake data of cluster 2 followed GEV and Logistics according to the results of the type of distribution test using the K-S test. The results can be shown detail in Table 8. Based on Table 8, it can be seen that the P-value of the GEV distribution is greater than the Logistics distribution so that it can be concluded that the $X_{2}$ earthquake data has a GEV distribution. The histogram graph and the density function of both distributions referred to can be shown with Fig. 13.b. Based on Fig. 13.b shows that the histogram and the density function graph are negatively skewed so that it can be concluded that the earthquake data in cluster $X_{2} 2$ is not normally distributed. On the other hand, $X_{2}$ earthquake data of cluster 3 follows the GEV and Logistics distribution. This is based on the K-S test results shown in Table 9. Based on Table 9, it can be concluded that the earthquake data of cluster $X_{2}$ is GEV distributed because the P-value is greater than the Logistics distribution. Next the histogram and the density function graph of GEV and Logistics distribution can be shown with Fig. 14.b. The histogram and the density function graph of GEV and Logistics distribution are shown negatively skewed in Fig. 14.b. The result shows that the $X_{2}$ earthquake cluster 3 data is not normally distributed. 

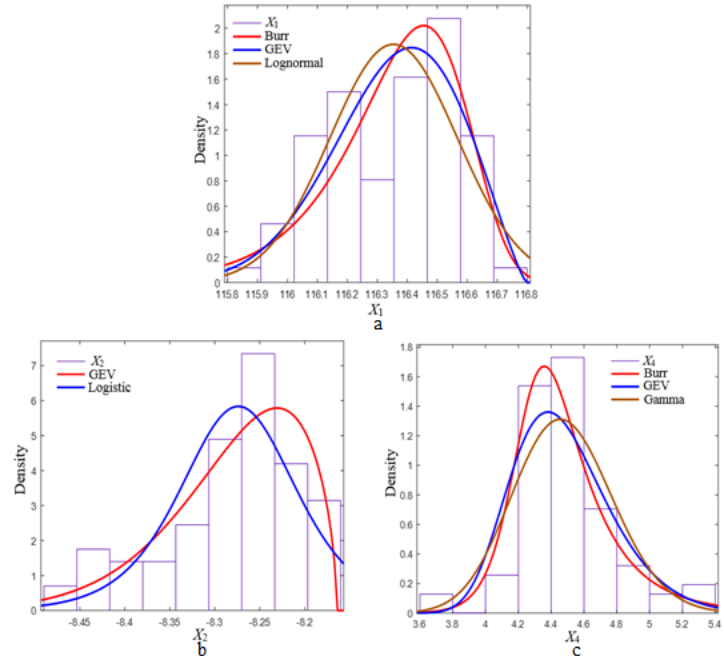

Figure 12. Histogram and Probability Density Function graph based on earthquake data a. $X_{1}$, b. $X_{2}$, and c. $X_{4}$ for cluster 1 in Province of NTB.
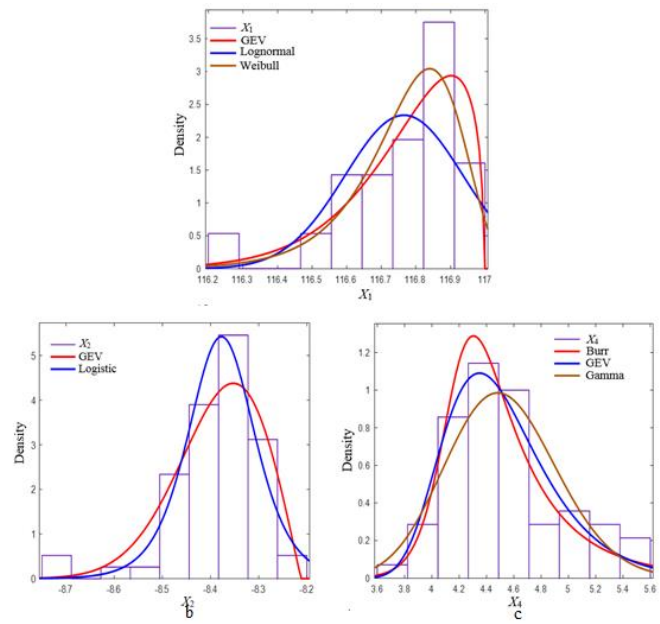

Figure 13. Histogram and Probability Density Function based on earthquake data a. $X_{1}$, b. $X_{2}$, and c. $X_{4}$ for cluster 2 in Province of NTB.

The $X_{3}$ earthquake data can only be appointed that distribution test results of $X_{3}$ earthquake data for cluster 3 because the $X_{3}$ earthquake data for clusters 1 and 2 do not fit one of the distributions. The results of testing the distribution type using the K-S test can be shown in Table 9. Table 9 shows that the Weibull distribution has a P-value greater than the Lognormal and Gamma distribution so that it can be concluded that the $X_{3}$ earthquake data of cluster 3 is Weibull distribution. The histogram and function of the third density of the intended distribution can be indicated by Fig. 14.c. Based on Fig. 14.c shows that the histogram and density function graph tend to be negatively skewed so that it can be said that $X_{3}$ earthquake data of cluster 3 is not normally distributed.

Based on the K-S test results with $\alpha=0.05$, it turns out that the $X_{4}$ earthquake data in Cluster 1 tends to follow three types of distribution, namely the Burr, GEV, and Gamma distribution as shown in Table 7. Based on Table 7, the distribution that tends to be approached by the $X_{4}$ earthquake data in cluster 1 is Burr distribution compared to GEV and Gamma distribution. The distribution graph can be shown with Fig. 12.c. Based on Fig. 12.c, it appears that the $X_{4}$ earthquake data in cluster 1 is more closed to the Burr distribution compared to the GEV and Gamma distribution. Furthermore, $X_{4}$ earthquake data cluster 2 was tested using the K-S test and $\alpha=0.05$ so the results can be shown with Table 8. Based on Table 8, it appears that $X_{4}$ earthquake data in Cluster 2 is closer to the Burr distribution. The histogram and density function graph of $X_{4}$ earthquake data in Cluster 2 can be shown with Fig. 13.c. Based on Fig. 13.c, shows that $X_{4}$ the earthquake data of cluster 2 follows the Burr distribution compared to the GEV and Gamma distribution. The earthquake $X_{4}$ earthquake data in Cluster 3 was also tested using the K-S test and $\alpha=$ 0.05 and the results can be shown detail in Table 9 . 

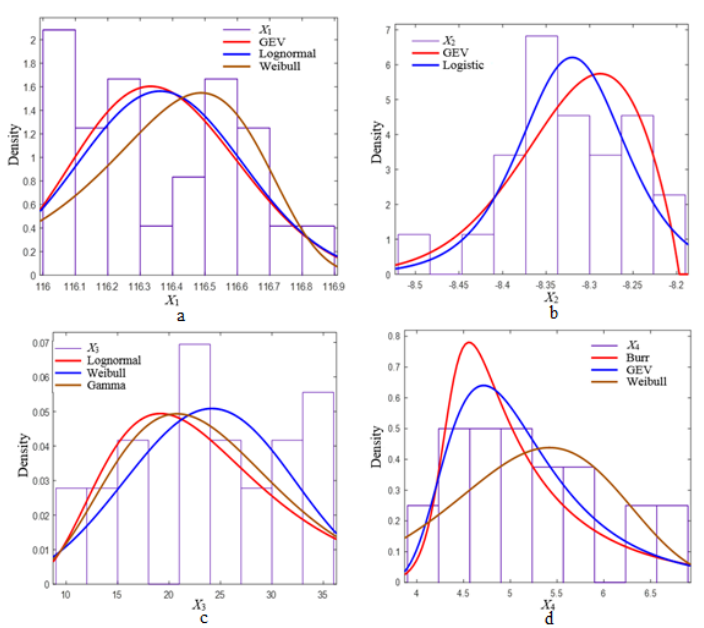

Figure 14. Histogram and Probability Density Function graph based on earthquake data a. $X_{1}$, b. $X_{2}$, c. $X_{3}$, and d. $X_{4}$ for cluster 3 in Province of NTB.

Based on the results in Table 9, X4 earthquake data of cluster 3 is closer to the Burr distribution when compared to the GEV and Weibull distribution. The histogram and its probability density function graph can be shown with Fig. 14.d. Based on Fig. 14.d, it can be seen that the histogram and density function of $\mathrm{X} 4$ earthquake data of cluster 3 are positively skewed so that it can be concluded that the cluster $X_{4}$ earthquake data of cluster 3 is not normally distributed.

Based on Fig. 12, Fig. 13, and Fig.14 shows that the histogram and density function graph from each of the $X_{1}, X_{2}, X_{3}$, and $X_{4}$ earthquake data (in Province of NTB) for cluster 1 , cluster 2 , and cluster 3 are either left or right skewed. This shows that the distribution of earthquake data $X_{1}, X_{2}, X_{3}$, and $X_{4}$ is not symmetrical so it can be concluded that the earthquake data $X_{1}, X_{2}, X_{3}$, and $X_{4}$ for cluster 1 , cluster 2 , and cluster 3 are not normally distributed.

\section{CONCLUSION}

Based on the significant discussion in the previous section, it can be concluded that the distribution of earthquakes in NTB Province is more dominant in North Lombok and East Lombok Regencies.

The earthquake in NTB Province was grouped into 3 clusters with the K-Means cluster approach method.

Based on the test results of distribution types using K-S test for cluster 1, cluster 2, and cluster 3, it was obtained that the distribution types on earthquakes consisted of :

a. Longitude data $\left(X_{1}\right)$ for cluster 1 following the Burr distribution, cluster 2 following the Weibull distribution, and cluster 3 following the GEV distribution;

b. Latitude data $\left(X_{2}\right)$ for cluster 1 , cluster 2 , and cluster 3 following the GEV distribution;

c. Depth data $\left(X_{3}\right)$ for cluster 1 and cluster 2 does not follow one type of distribution while cluster 3 follows the GEV distribution; and

d. Magnitude data $\left(X_{4}\right)$ for cluster 1, cluster 2 and cluster 3 following the Burr distribution.

This research can be expanded by grouping earthquake events in the regency in NTB Province using the concept of hierarchical cluster method. Then it must be progressed by determining the type of distribution of each cluster.

\section{Acknowledgement}

The authors would like to thank FMIPA Unpatti because this research described in this paper was supported by a grant 2019 from Faculty 
of Mathematics and Natural Sciences Pattimura University (FMIPA Unpatti) Ambon - Indonesia.

\section{Conflict of Interest}

Since the researcher is solely here, there is no conflict in all of her scientific data and cooperation.

\section{References}

[1]. Villenewe, M., Martin, R., Bellon, H., Rehault, J. P., Jean, Cornee, J., Bellier, O., Burhannudin, S., Hinschberger, F., Honthaas, C., dan Monnier, C., Deciphering of Six Blocks of Gondwana Origin within Eastern Indonesia (South East Asia), Gondwana Research, Elsevier (2010).

[2]. Zulfakriza, Nugraha, A. D., Widiyantoro, S., Puspito, N.T., Sahara, N.P., Gempa Lombok dan Gempa Palu (Tinjauan Seismologi), Kelompok Keahlian Geofisika Global, FTTM - ITB (2018).

[3]. Indonesian Tectonic Plates

(Source:http://www.drgeorgepc.com/Tsunami1833 Indonesia. html).

[4]. Rochester, W.A., Skewes, T.D., Suadnya, I.W., Butler, J.R.A., Lyne, V.D., Handayani, T., Habibi, P., Karnan, and Cokrowati, N., A typology of natural resource use for livelihood impact assessments in Nusa Tenggara Barat Province, Indonesia, Climate Risk Management 12, pp. 59-68 (2016).

[5]. Alfonsi, L., Piersanti, A., dan Spada, G., Did the 1977 Sumba earthquake excite the Chandler wobble?, Yarth and Planetary Science Letters 153, pp. 287-292 (1997).

[6]. Kementrian Sosial, Penanganan Korban Bencana Gempa Bumi Provinsi Nusa Tenggara Barat, (2018).

[7]. Parwanto, N.B., Oyama, T., A statistical analysis and comparison of historical earthquake and tsunami disasters in Japan and Indonesia, International Journal of Disaster Risk Reduction 7, pp. 122-141 (2014).

[8]. Gunawardana, P.M., Morra, G., Correlation between elastic energy density and deep earthquakes distribution, Journal of Geodynamics 106, pp. 33-45 (2017).

[9]. Zuo, R., Agterberg, F. P., Cheng, Q., Yao, L., Fractal characterization of the spatial distribution of geological point processes, International Journal of Applied Earth Observation and Geoinformation 11, pp. 394-402 (2009).
[10]. Wattimanela H J, Pasaribu, U.S., Puspito, N.T., Indratno, S.W., Classification of Earthquake Distribution in the Banda Sea Collision Zone with Point Process Approach, International Journal of Environmental, Chemical, Ecological, Geological and Geophysical Engineering 9(12), pp. 1324-1325 (2015).

[11]. Oikonomou, C., Haralambous, H., Muslim, B., Investigation of ionospheric precursors related to deep and intermediate earthquakes based on spectral and statistical analysis, Advances in Space Research 59, pp. 587-602 (2017).

[12]. Beccar-Varelaa, M. P., Gonzalez-Huizar, H., Mariania, M.C., Tweneboah, O.K., Use of wavelets techniques to discriminate between explosions and natural earthquakes, Physica A 457, pp. 42-51 (2016).

[13]. Brown, J. R., Beroza, G. C., dan Shelly, D.R., An Autocorelation Method to Detect Low Frequency Earthquakes Within Tremor, Geophysical Research Letters 35, LI6305, pp. 1-5 (2008).

[14]. Morrison, Multrivariate Statistical Methods, McGraw Hill, Tokyo (1990).

[15]. Jennings, P. J., Using Cluster Analysis to Define Geographical Rating Territories, Discussion Paper Program, F Casualty Actuarial Society, MAAA (2008).

[16]. Mils, R. T., Hoffman, F. M., Kumar, J., dan Hargrove, W. W., Cluster Analysis-Based Approaches for Geospatiotemporal Data, Mining of Massive Data Sets for Identification of Forest Threats, International Conference on Computational Sciences (ICCS), Procedia Computer Science 4, pp. 1612-1621 (2011).

[17]. Walpole, R.E, Myers R.H, Myers, S.L., Ye K., Probability and Statistica for Engineers and Scientist, Prentice Hall (2011).

[18]. Simard, R., L'ecuyer, P., Computing The Two-Sided Kolmogorov-Smirnov Distribution, J. Stat. Softw. 39, pp. 1-18 (2011).

[19]. Chambers J., Cleveland, W., Kleiner, B., and Tukey, P., Graphical Methods for Data Analysis, Wadsworth (1983).

[20]. Marsaglia, G., Tsang, W.W., Wang, J., Evaluating Kolmogorov's Distribution. J. Stat. Softw. 8, pp. 1-4 (2003).

[21]. C.V. Maharani, Statistics of Nusa Tenggara Barat Province, Nusa Tenggara Barat in Figure (2018). ISSN 0215-2215.

[22]. United States Geological Survey (USGS): Retrieved from https://earthquake.usgs.gov/earthquakes /search/: Downloaded on January 22, 2019. 


\section{'Corresponding Authors CV:}

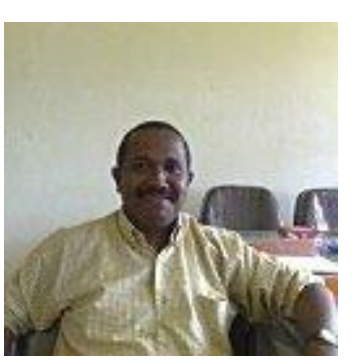

${ }^{+}$Assoc.Prof. Dr. H. J. Wattimanela, S.Si, M.Si is an experienced scientist (a senior associate professor) especially in the field of statistics. Dr. Wattimanela has studied statistics since he took the B.Sc. (S.Si) and M.Sc. (M.Si) degrees in Mathematics Department at Gadjah Mada University (UGM), Yogyakarta, Central Java in 1996 until present. The Dr in mathematical statistics degree was from Mathematics Study Program of Bandung Technology Institute (ITB), Bandung, West Java, Indonesia. In addition, he has succeeded in educating more than 53 students of Mathematics Department at Pattimura University. In 2011, he was honored with Satyalancana Karya Satya X Years from Mr. President of Indonesian.

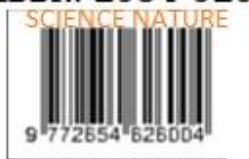

